\title{
Suicidalitet hos eldre med psykoselidelser
}

\author{
Ved Kjell Martin Moksnes
}

\begin{abstract}
I over 50 år har det vært høy forekomst av selvmord blant eldre. Forskning har vist at selvmordsforsøk blant eldre oftere ender med selvmord enn selvmordsforsøk blant yngre. Autopsistudier viser at opp mot $97 \%$ av eldre som tar sitt liv, fyller kriteriene for en psykiatrisk diagnose, særlig depresjon. I denne artikkelen fokuseres det på risikofaktorer for selvmord ved psykoselidelser hos eldre.
\end{abstract}

Selvmordsraten blant eldre er høy i de fleste land. Personer over 60 år sto for 23 $\%$ av alle selvmord i Norge i 2007, selv om de kun representerte $13 \%$ av befolkningen. Denne tendensen har vært til stede gjennom 50 år, både hos kvinner og menn (tab. 1). De siste 30 årene har menn mellom 20 og 29 år nådd samme høye nivå som eldre menn. De siste årene er det registrert en nedgang hos personer over 70 år (fig. 1). Vi vet at selvmordsrisikoen er 10-15 ganger høyere hos pasienter med alvorlig psykisk lidelse. Flere studier viser at 70-97 \% av selvmord blant eldre er forbundet med psykiatrisk sykdom, og depresjon er den dominerende lidelsen (Waern, Runeson, Allebeck, Beskow, Rubenowitz et al., 2002).

Selvmordsfors $\varnothing \mathrm{k}$ hos eldre ender oftere med selvmord enn hos yngre. Forholdet mellom selvmordsfors $\varnothing \mathrm{k}$ og gjennomf $\varnothing \mathrm{rte}$ selvmord hos eldre har blitt estimert til mellom 2:1 og 4:1, mens forholdet ligger mellom 8:1 og 15:1 for befolkningen som helhet, og 200:1 for yngre personer (De Leo, Padoani, Scocco, Lie, Bille-Brahe et al., 2001). Eldre snakker mindre om planene, og selvmord er derfor vanskeligere å forutsi og forebygge. Menn synes å være mer besluttsomme enn kvinner når de har suicidal hensikt, og denne forskjellen blir mer uttalt ved høyere alder (Dombrovski, Butters, Reynolds, Houck, Clarket al., 2008).

\section{Metode}

Artikkelen er basert på klinisk erfaring, gjennomgåelse av læreb $\varnothing$ ker og s $\varnothing \mathrm{k}$ via PubMed. Temaet er omtrent ikke omtalt i norske og engelske læreb $\varnothing$ ker. S $\varnothing$ keordene "Psychosis and elderly" ga 112 treff, "Suicide and elderly" 97 treff, mens "Suicide and psychosis and elderly" ga fire treff. Eldre er her definert som personer 65 år og eldre. På grunn av den sparsomme forskningsaktivitet har en også sett på studier med personer opp i 60-årsalder og hvordan de skiller seg fra yngre personer.

Psykoser hos eldre omfatter i artikkelen affektive psykoser, personer med schizofreni som blir eldre eller har sen debut eller meget sent debuterende schizofreniliknende sykdom. I tillegg inkluderes spesifikke sykdommer som rammer eldre slik som vrangforestillingslidelse, akutt konfusjon og ulike typer demens med symptomer og manifestasjoner som kan sidestilles med psykose. Personer med Alzheimers sykdom og vaskulær demens har ofte manglende innsikt. Hallusinasjoner og vrangforestillinger er til stede hos ca. $20 \%$, og hos pasienter med lewylegemesykdom er forekomsten hele $75 \%$.

\section{Ulike sykdommer som risikofaktorer hos eldre}

Psykose

Selvmordstanker forekommer ofte hos psykotiske pasienter. Ved analyse av psykotiske symptomer som risikofaktor var funnene selvmotsigende. Hos yngre personer ser det ut som innsikt i sykdommen, få år i behandling og alvorlige depresjonssymptomer $\varnothing$ ker pasientenes selvmordsrisiko signifikant, men det er usikkert om dette gjelder eldre (Schwartz \& Smith, 2004).

\section{Schizofreni}

Halvparten av eldre personer med schizofreni har fors $\varnothing \mathrm{kt}$ å ta sitt liv en eller annen gang i forlфpet av sykdommen. Fors $\varnothing$ kene har gjerne vært knyttet til en periode med dyp depresjon og håpløshetsfølelse. Helsepersonell må derfor ha en kontinuerlig årvåkenhet med denne pasientgruppen. Blant eldre som tok sitt liv, lider 2-6\% av schizofreni. Risikoen er høyest i yngre aldersgrupper, men den er høy helt opp til 70-årsalder (Osborn, Levy, \& King, 2008). En meta-analyse konkluderer med at både hallusinasjoner og vrangforestillinger er beskyttende, mens befalende hallusinasjoner tenderer til å gi høyere risiko for selvmord (Nordentoft, 2007).

\section{Depresjon}

Depresjon er en vanlig lidelse hos eldre, og finnes hos $71 \%-82 \%$ av alle som tar sitt eget liv (Waern et al., 2002). Selv milde og moderate depresjoner er en risikofaktor. Eldre personer med depresjon har fire ganger høyere risiko for selvmord enn yngre med depresjon. Omtrent $20 \%$

Tabell 1. Selvmordsrate per 100.000 innbyggere i Norge 1951-2005. Eldre menn og kvinner er sammenliknet med gjennomsnittet for alle aldersgruppene Menn

\begin{tabular}{|l|c|c|c|c|c|c|c|c|c|}
\hline Alder & $1951-55$ & $1961-65$ & $1971-75$ & $1976-80$ & $1981-85$ & $1986-90$ & $1991-95$ & $1996-00$ & $2001-05$ \\
\hline $60-69$ & 25,0 & 20,9 & 22,0 & 25,2 & 28,8 & 30,6 & 27,4 & 24,6 & 18,2 \\
\hline $70+$ & 18,1 & 19,2 & 19,4 & 23,4 & 23,5 & 29,8 & 27,8 & 24,7 & 23,0 \\
\hline Alle aldre & 11,1 & 11,6 & 13,8 & 17,2 & 20,7 & 22,9 & 20,5 & 18,4 & 16,4 \\
\hline
\end{tabular}

Kvinner

\begin{tabular}{l|c|c|c|c|c|c|c|c|c}
\hline Alder & $1951-55$ & $1961-65$ & $1971-75$ & $1976-80$ & $1981-85$ & $1986-90$ & $1991-95$ & $1996-00$ & $2001-05$ \\
\hline $60-69$ & 8,2 & 5,8 & 8,6 & 9,7 & 12,0 & 13,1 & 12,1 & 8,9 & 8,5 \\
\hline $70+$ & 4,5 & 4,5 & 4,0 & 4,3 & 6,6 & 8,9 & 8,8 & 5,9 & 5,0 \\
\hline Alle aldre & 3,3 & 3,4 & 4,7 & 6,3 & 7,3 & 8,2 & 7,1 & 6,3 & 6,4 \\
\hline
\end{tabular}

Tallene er årsgjennomsnitt for perioden 


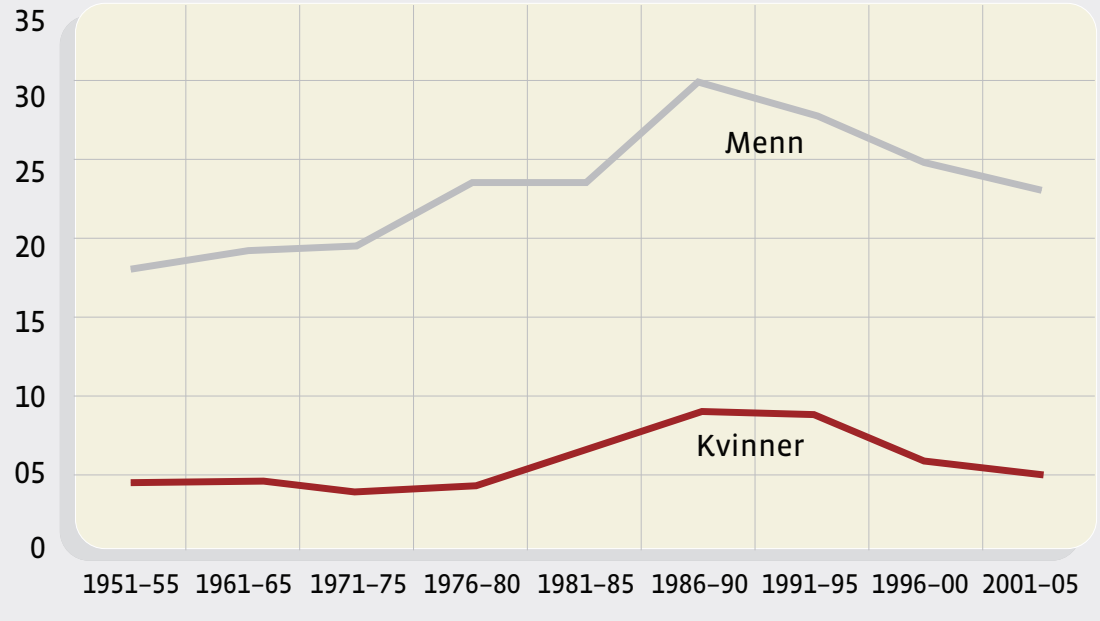

*Årsgjennomsnitt i perioden

av hospitaliserte pasienter med alvorlig depresjon har vrangforestillinger og hallusinasjoner, og møter kriteriene for en psykotisk depresjon. Disse oppnår gjerne dårligere resultat av behandlingen, har større risiko for tilbakefall, høyere dødelighet og en større risiko for selvmordsfors $\varnothing \mathrm{k}$ og selvmord enn pasienter med ikke-psykotisk depresjon. Økende alder var faktisk assosiert med lavere intensitet av suicidalitet ved psykotisk depresjon (Schaffer, Flint, Smith, Rothschild, Mulsant et al., 2008). Noen mener at håpløshet er en sterk prediktor for selvmord, endog sterkere enn graden av depresjon. Psykotisk depresjon er mer utbredt hos eldre, og disse har mer lesjoner i hvit substans, cerebrovaskulære og nevrodegenerative forandringer. Forandringene ses ofte i frontal- og temporallappene og svekker pasientens evne til planlegging og kontroll. Personer med psykotisk depresjon har mer agitasjon og ubesluttsomhet, men likevel er selvmord fem ganger vanligere enn ved alvorlige depresjoner uten psykose (Gaudiano, Young, Chelminski, \&

Zimmerman, 2008). I denne studien var det ingen aldersforskjell mellom gruppene psykotisk og ikke-psykotisk depresjon.

\section{Bipolare pasienter}

Bipolar affektiv lidelse med debut i eldre år representerer ca. 10 \% av alle psykiatriske innleggelser i eldre år. Aizenberg, Olmer, og Barak (2008) fant i en foreløpig rapport hyppigere selvmordsfors $\varnothing \mathrm{k}$ i denne gruppen. Irritabilitet og psykomotorisk agitasjon er de sterkeste prediktorer for selvmordsfors $\varnothing$ k. I en stor prospektiv studie over to år hadde eldre pasienter med tidlig debut, oftere et forl $\varnothing p$ med hurtige svingninger av sykdommen og færre selvmordsfors $\varnothing \mathrm{k}$ enn de med sen debut (Oostervink, Boomsma, Nolen, \& The Emblem Advisory Board, 2008). Bipolare pasienter med selvmord i familien har tre ganger høyere risiko for selvmord i et livsløpsperspektiv. Eldre bipolare pasienter har oftere en blanding av depressive og maniske manifestasjoner samtidig, noe som kan $\varnothing$ ke risikoen for selvmord (Dilsaver, Chen, Swann, Shoaib, \& Krajewski, 1994).

\section{Hjerneorganiske lidelser}

Kognitiv svekkelse og demens

Mange deprimerte eldre har kognitiv svekkelse. Er de fortvilt, skal de betraktes som en høyrisikogruppe (Ayalon, Mackin, Arean, Chen, McDonel Herr et al., 2007). Den kognitive reduksjon kan gi svekket problemløsende evne. I tidlig fase av $\mathrm{Alz}$ heimers sykdom mangler mer enn halvparten innsikt $i$ at de lider av en sykdom. Sykdommen hemmer evnen til å gjenkjenne egen svekkelse og dette skyldes nok først og fremst sykdommens biologi og ikke en psykologisk benektning. Mange av pasientene er ikke rasjonelle, og selv om det ikke foreligger en tradisjonell psykose, kan tilstanden av og til sidestilles med en alvorlig sinnslidelse. Eldre deprimerte pasienter med selvmordsfors $\varnothing \mathrm{k}$ og alvorlige selvmordstanker hadde dårligere kognitive og eksekutive funksjoner sammenlignet med ikke-suicidale deprimerte eldre (Dombrovski et al., 2008).

Av personer med demens som blir innlagt i psykiatrisk avdeling, blir en av ti innlagt etter selvmordsfors $\varnothing \mathrm{k}$. А få diagnosen demens under et sykehusopphold gir en høyere selvmordsrisiko. I en stor registerbasert studie fra Danmark er selv- mordsraten blant personer med demens høyest i aldersgruppen 50-69 år. Disse hadde 8-10 ganger høyere risiko enn de uten en slik diagnose, når diagnosen ble stilt mens de var i sykehus. De over 70 år hadde en tre ganger høyere risiko (Erlangsen, Zarit, Tu, \& Conwell, 2006). En av grunnene kan være at diagnosen demens i yngre eldre alder er relativt uvanlig og uventet. $\AA$ ha en ektefelle var ingen beskyttende faktor i denne gruppen. Risikoen var st $\varnothing$ rst det første halvåret etter at diagnosen var stilt på sykehuset. Blant demenssykdommene er risikoen ved Alzheimers sykdom større enn ved vaskulær demens, og samtidig depresjon $\varnothing \mathrm{kte}$ risikoen. Vi vet også at personer med demens har evne til å planlegge og gjennomføre selvmordsfors $\varnothing \mathrm{k}$ flere år etter at diagnosen er stilt (Erlangsen, Zarit og Conwell, 2008; Purandare, Voshaar, Rodway, Bickley, Burns et al., 2009). Selvmordsraten har vært regnet som lav og er beskrevet både ved Alzheimers sykdom, vaskulær-, alkoholisk og lewylegemedemens. Tilstedeværelsen av vrangforestillinger $\varnothing$ ker selvmordsrisikoen med 32 ganger mer enn hos den $\varnothing$ vrige befolkningen (Jorgensen, 1994). Faren ser ut til å være st $\varnothing$ rst i de tidlige stadier av demenssykdommen, særlig hos menn med høyere utdannelse. Manglende innsikt og eksekutiv dysfunksjon kan synes å beskytte mot selvmord da dette minsker evnen til å planlegge og utføre en slik handling (Lim, Rubin, Coats, Morris et al., 2005).

\section{Hjerneslag}

Opp mot halvparten av hjerneslagpasientene utvikler depresjon. Mange har liten introspektiv evne og problemer med å fortelle om sin emosjonelle tilstand. $\AA$ gjenkjenne symptomene og komme raskt i gang med behandling er en stor utfordring for behandlerne. Tendensen til spontan remisjon er liten. Akutt konfusjon er nokså vanlig, og vrangforestillinger forekommer hos $30 \%-60 \%$ som har utviklet multi-infarktdemens etter flere hjerneslag. Sammen med synshallusinasjoner er dette enda mer vanlig hos personer med demens av levylegemetype. Aggresjonen noen viser er ofte knyttet til følelsen av hjelpeløshet, fortvilelse, angst og vrangforestillinger. Selvmordet kan skyldes svekket kontroll og at tilstanden kjennes for tung å bære. En svekket 


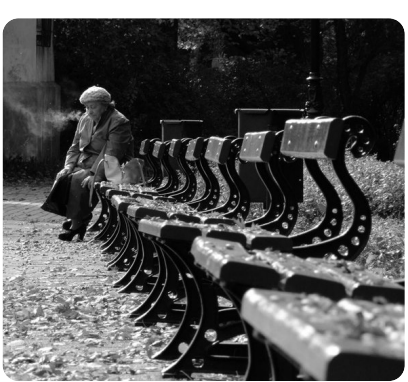

frontallappsfunksjon kan $\varnothing$ ke risikoen for impulsive selvmordsfors $\varnothing \mathrm{k}$.

\section{Andre hjerneorganiske lidelser}

Mange forfattere har beskrevet $\varnothing \mathrm{kt}$ forekomst av selvmord hos pasienter i tidlig fase av Huntington-Lunds chorea. På dette tidspunkt må ofte arbeidsforholdet avsluttes og førerkortet innleveres. I senere faser tilpasser pasienten seg sykdommen og aksepterer diagnosen og fremtidsutsiktene (Paulsen, Nehl, Hoth, Kanz, Benjamin et al., 2005). Parkinsons sykdom er en invalidiserende lidelse som er forbundet med høy forekomst av depresjon. Dyp depresjon kombinert med manglende impulskontroll og psykose $\varnothing$ ker forekomsten av selvmordstanker (Nazem, Siderowf, Duda, Brown, Ten Have et al., 2008). Epilepsi forekommer hyppigst hos eldre, og det er fem ganger $\varnothing \mathrm{kt}$ forekomst av selvmord. Ved temporallappsepilepsi er risikoen enda større. Anfallene kan gjøre pasienten forvirret, og postiktalt forekommer paranoide vrangforestillinger, synsog hørselshallusinasjoner og blokkering av tankeevnen som $\varnothing$ ker risikoen.

\section{Metabolske forstyrrelser}

Hyperkalsemi kan føre til en akutt paranoid tilstand med depresjon. Eldre som er sensitive for hyperkalsemi kan bli svært voldelige og flere tilfelle av selvmord har forekommet.

\section{Hospitaliserte og nylig utskrevne pasienter}

Mange tar livet sitt mens de er inneliggende i en psykiatrisk avdeling, særlig første uke etter innleggelsen og uken etter utskrivningen. I Nord-Finland skjedde nesten halvparten av selvmordene innen de tre første måneder etter utskrivning, og eldre kvinner var mest utsatt.

\section{Aktuelle intervensjoner}

\section{Forebygging}

Forebygging av selvmord er en prioritert oppgave for helsevesenet. Alt som kan bedre eldre menneskers levevilkår og livskvalitet, vil være med å forebygge selvmord. A redusere sykdom, ulykker, skilsmisser, alkoholbruk og smerte for den enkelte vil være forebyggende på flere måter. Likeledes å motarbeide krefter som får eldre til å bestemme seg for at det ikke lenger er noen plass for dem, og at det ikke lenger er noe å kjempe for. Det viktigste forebyggende tiltak for enkeltpersoner er at depresjon diagnostiseres tidlig og behandles adekvat. Ved alvorlig selvmordsfare bør pasienten henvises til psykiater eller innlegges i sykehus. Her kan andre tiltak settes inn som beskyttelse, samtalebehandling, legemiddelbehandling, elektrostimulasjonsbehandling og st $\varnothing$ ttegruppe. Helsepersonells kompetanse må sikres, og akuttpsykiatriske avdelinger må ha en lav terskel for innleggelse av eldre med depresjon og selvmordstanker, også om de lider av en hjerneorganisk sykdom inkludert demens. Kliniske ferdigheter må bedres blant helsepersonell for å gjenkjenne pasienter med høy risiko og klare å behandle dem optimalt. Forst og fremst handler det om å oppfatte pasientenes tanker og d $\varnothing$ ds $\varnothing$ nsker. Enhver følelse av hjelpeløshet, håpløshet, skyld og tap av evnen til å glede seg må tas alvorlig. Eldre pasienter som er i høyrisikogruppen for selvmord og som ikke straks kan innlegges i en psykiatrisk akuttavdeling, skal følges tett opp av psykiater og team for å beskytte pasienten, etablere trygge omgivelser og starte behandling av den psykiatriske lidelse. De fleste foretrekker å hospitalisere pasienter med psykotisk depresjon. På grunn av den høye forekomst av selvmord ved permisjoner og det første året etter utskrivning må selvmordsrisikoen kontinuerlig evalueres, og det er viktig med en trygg og god oppfølgende behandling for å forhindre selvmord og tilbakefall ved behandling av depresjon (AjdacicGross, Lauber, Baumgartner, Malti, \& Rössler, 2009).

\section{Behandling i primærhelsetjenesten}

Eldre pasienter opps $\varnothing$ ker ofte sin fastlege den siste måneden før selvmordet, hvilket viser at fastlegen kan ha en vital rolle $\mathrm{i}$ å forebygge selvmord i denne aldersgruppen (Pfaff \& Almeida, 2005). Pasientens fortvilelse og kognitive fungering unders $\varnothing$ kes. Allerede i f $\varnothing$ rste samtale skal helsepersonell aktivt spørre pasientene om de har selvmordstanker. Mange opplever det som en avlastning å få snakke med en annen person om dette. En udiagnostisert og ubehandlet depresjon kan foreligge, og en bør være kritisk til pasientens tilsynelatende rasjonelle $\varnothing$ nske om å få $\mathrm{d} \phi$, hvis ikke pasienten er i en terminal fase av livet. Selvmord ved fravær av depresjon er svært sjelden hos eldre. Det er viktig å lage en avtale med pasienten om villighet til å motta behandling og motstå trangen til selvmord. Legen inviterer pasienten til å ta kontakt om selvmordstankene blir påtrengende. Noen pasienter med psykose og bipolar lidelse har dessverre ikke så god kontakt med primærlegen som $\varnothing$ nskelig og de møter høyere terskler for å bli tatt hånd om sammenliknet med personer uten psykose.

Tilgangen til medisinsk og psykologisk behandling må bedres for denne gruppen. De kan trenge rask behandling og omsorgsfull oppfølging over tid.

\section{Biologisk behandling}

Erfaring viser at behandling med antidepressiver og/eller litium har en klar selvmordsforebyggende effekt, men det er kun vist hos menn opp mot 60-årene (Olfson $\&$ Marcus, 2008). Depresjonsfaser hos bipolare pasienter kan være særlig behandlingsresistente. Pasienter med selvmordstanker skal følges tett opp og behandles etter gjeldende retningslinjer. Samtalebehandling må gå hånd $\mathrm{i}$ hånd med den biologiske behandling.

Klozapin reduserer suicidal atferd mer enn olanzapin hos voksne pasienter med schizofreni og schizoaffektiv lidelse (Glick, Zaninelli, Hsu, Young, Weiss et al., 2004). Ved tidlig intervensjon ved psykose har en preliminært funnet holdepunkter for å forebygge tilbakefall, innleggelsesfrekvens, selvmordsrater og behandlingskostnader, men det er ikke vist at dette gjelder eldre (Ricciardi, McAllister, Dazzan et al., 2008). En tilpasset kognitiv atferds terapeutisk tilnærming kan benyttes i behandlingen av pasienter med psykotisk depresjon. Personer med demens må få tilstrekkelig konsultasjonstid, oppfølging og praktisk hjelp i tiden etter diagnostisering, og sammen med pårørende forsikres om at de vil få den hjelpen de har behov for fremover. Pasientene har ofte nytte av behandling med antidepressiver i kombinasjon med atypiske antipsykotika, dersom vrangforestillinger er til stede. Det handler om å bruke små doser risperidon og quetiapin, men faren for kardiovaskulære bivirkninger må overveies (Yang, Tsai, \& Hwang, 2005). Eldre suicidale pasienter krever spesiell oppmerksomhet i forløpet av behandlingen fordi de har en lavere respons og trenger lenger tid på å respondere (Szanto, Mulsant, Houck, Dew, \& Reynolds, 2003). 
Elektrokonvulsiv terapi (ECT) er et alternativ for psykotisk deprimerte eldre med høy selvmordsrisiko fordi effekten inntrer hurtigere, og hele $90 \%$ oppnår bedring (Dubovsky \& Dubovsky, 2008). Tre studier viser også lavere dødelighet etter behandling med ECT. Med adekvat antidepressiv legemiddelbehandling etter ECT får færre tilbakefall det første året (Birkenhäger, Pluijms, \& Lucius, 2003). Eldre blir i st $\varnothing$ rre grad enn yngre kvitt sine selvmordstanker (Kellner, Fink, Knapp, Petrides, Husain et al., 2005).

Folkehelsebeslutninger om å redusere bruken av antidepressiver kan komme til å $\varnothing$ ke antall selvmord (Cougnard, Verdoux, Grolleau, Moride, Begaud, \& Tournier, 2008). Mangelfull respons på behandling av depresjon sent i livet er en stor utfordring. Minst halvparten av de eldre responderer ikke tilfredsstillende på første behandling med et antidepressivum, selv ved optimale behandlingsbetingelser. Når remisjon ikke oppnås, $\varnothing$ ker risikoen for tilbakefall. Behandleren må være aktiv og forsterke behandlingen inntil remisjon oppnås og fortsette behandlingen for å forebygge tilbakefall. I flere studier der pasienter ikke responderte på SSRI eller SNRI, ser 50 \% ut til å få remisjon etter at et tilleggsmedikament, eller et supplerende antidepressivum ble lagt til den primære behandlingen (Lenze, Sheffrin, Driscoll, Mulsant, Pollock et al., 2008). $\mathrm{N} \varnothing l$ ikke med å henvise til ECT om nødvendig.

\section{Psykososiale behandlingsformer}

Andre intervensjoner handler om å oppheve sosial isolasjon, styrke nettverket, behandle tilleggsproblemer som alkohol og tablettmisbruk, og begrense adgangen til skytevåpen (Lim et al., 2005). Innleggelse kan også være til god hjelp for å skape en sikrere ramme rundt pasienten de første ukene før behandlingen virker. Eldre må få en tett oppfølgende behandling etter utskrivning med riktig bruk av legemidler kombinert med samtalebehandling (Karvonen, Hakko, Koponen, Meyer-Rochow, \& Räsänen, 2009).

Det er behov for studier blant eldre med psykoser og selvmordsrisiko. Eldre med psykoser har gjerne vært ekskludert fra studier. Vi vet at eldre med selvmordstanker og -planer fortsatt har en høy risiko for selvmord, og at psykotiske symptomer kan $\varnothing$ ke denne risikoen. Sannsynligvis kan $\varnothing \mathrm{kt}$ satsing på forebyggende tiltak og bedret tilgang til god behandling føre til en bedre fremtid for mange.

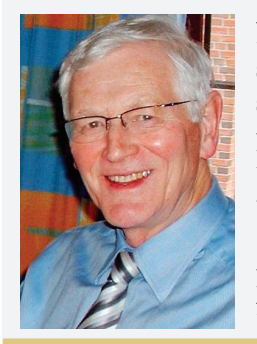

Kjell Martin Moksnes er spesialist i psykiatri og seksjonsoverlege ved Alderspsykiatrisk avdeling, Oslo universitetssykehus, Ullevål. Han har blant annet 10 års erfaring fra akuttpsykiatri og 24 års erfaring fra alderspsykiatri.

\section{Referanser}

Aizenberg, D., Olmer, A. \&Barak, Y. (2006). Suicide attempts amongst elderly bipolar patients. J Affect attempts amongst
Disord, 91, 91-94.

Ajdacic-Gross, V., Lauber, C., Baumgartner, M., Malti, T., \& Rössler, W. (2009). In-patient suicide - a 13 . year assessment. Acta Psychiatr Scand, 120(1), 71-75. Ayalon, L., Mackin, S., Arean, PA., Chen, H., \& McDonel Herr EC. (2007). The role of cognitive functioning and distress in suicidal ideation in older adults. J Am Geriatr Soc, 55, 1090-1094.

Birkenhäger, TK., Pluijms, EM., \& Lucius, SAP. (2003). ECT response in delusional versus non-delusional depressed inpatients. J Affect Disord, 74, 191-195.

Cougnard, A., Verdoux, H., Grolleau, A., Moride, Y., Begaud, B., \& Tournier M. (2008). Impact of antidepressants on the risk of suicide in patients with depression in reallife conditions: a decision analysis model. Psychol Med, 9, 1-9.

De Leo, D., Padoani, W., Scocco, P., Lie, D., BilleBrahe, U., Arensman, E. et al. (2001). Attempted and completed suicide in older subjects: results from the WHO/EURO multicentre study of suicidal behaviour. Int J Geriatr Psychiatry, 16, 300-310.

Dilsaver, SC., Chen, YW., Swann, AC., Shoaib, AM., \& Krajewski, KJ. (1994). Suicidality in patients with pure and depressive mania. Am J Psychiatry, 151(9), 1312-1315.

Dombrovski, AY., Butters, MA., Reynolds, CF 3rd., Houck, PR., Clark, L., Mazumdar, S. et al. (2008). Cognitive performance in suicidal depressed elderly: preliminary report. Am J Geriatr Psychiatry, 16(2), 109-115.

Dubovsky, SL., \& Dubovsky, AN. (2008). Mood disorders and the outcome of suicidal thoughts and attempts. Crit Care Clin, 24(4), 857-874.

Erlangsen, A., Zarit, SH., Tu, X., \& Conwell, Y. (2006). Suicide among older psychiatric inpatients: an evidence-based study of a high-risk group. Am J Geriatr Psychiatry, 14, 734-741.

Erlangsen, A., Zarit, SH., \& Conwell, Y. (2008). Hospital-diagnosed dementia and suicide: a longitudinal study using prospective, nationwide registe data. Am J Geriatr Psychiatry, 16, 220-228.

Gaudiano, BA., Young, D., Chelminski, I., \& Zimmerman, M. (2008). Depressive symptom profile and severity patterns in outpatients with psychotic vs nonpsychotic major depression. Compr Psychiatry, 49(5), 421-429.

Glick, ID., Zaninelli, R., Hsu, C., Young, FK., Weiss, L., Gunay, I. et al. (2004). Patterns of concomitant psychotropic medication use during a 2-year study comparing clozapine and olanzapine for the prevention of suicidal behavior. J Clin Psychiatry, 65(5), 679-685.
Jorgensen, P. (1994). Course and outcome in delusional beliefs. Psychopathology, 27, 583-587.

Karvonen, K., Hakko, H., Koponen, H., Meyer-Rochow, VB., \& Räsänen, P. (2009). Suicides among older persons in Finland and time since hospitalization discharge. Psychiatr Serv, 60(3), 390-393.

Kellner, CH., Fink, M., Knapp, R., Petrides, G., Husain, M., Rummans, T. et al. (2005). Relief of expressed suicidal intent by ECT: a consortium for research in ECT study. Am J Psychiatry, 162, 977-982.

Lenze, EJ., Sheffrin, M., Driscoll, HC., Mulsant, BH., Pollock, BG., Dew, MA. et al. (2008). Incomplete response in late-life depression: getting to remission. Dialogues Clin Neurosci, 10(4), 419-430.

Lim, WS., Rubin, EH., Coats, M., \& Morris, JC. (2005) Early-stage Alzheimer disease represents increased suicidal risk in relation to later stages. Alzheimer Dis Assoc Disord, 19, 214-219.

Nazem, S., Siderowf, AD., Duda, JE., Brown, GK., Ten Have, T., Stern, MB., \& Weintraub, D. (2008). Suicidal and death ideation in Parkinson's disease. Mov Disord, 23(11), 1573-1579.

Nordentoft, M. (2007). Prevention of suicide and attempted suicide in Denmark. Epidemiological studies of suicide and intervention studies in selected risk groups. Dan Med Bull, 54(4), 306-369.

Olfson, M., \& Marcus, SC. (2008). A case-control study of antidepressants and attempted suicide during early phase of major depressive episodes. J Clin Psychiatry, 69(3), 425-432.

Oostervink, F., Boomsma, MM., Nolen, WA., \& The Emblem Advisory Board. (2009). Bipolar disorder in the elderly, different effects of age and of age of onset. J Affect Disord, 116(3), 176-183.

Osborn, D., Levy, G., \& King, M. (2008). Suicide and severe mental illnesses. Cohort study within the UK general practice research database. Schizophrenia Res, 99(1-3), 134-138.

Paulsen, JS., Nehl, C., Hoth, KF., Kanz, JE., Benjamin, M., Conybeare, R. et al. (2005). Depression and stages of Huntington's disease. J Neuropsychiatry Clin Neurosci, 17(4), 496-503.

Pfaff, JJ., \& Almeida, OP. (2005). Detecting suicidal ideation in older patients: identifying risk factors within the general practice setting. Br J General Practice, 55, 269-273.

Purandare, N., Voshaar, RCO., Rodway, C., Bickley, H., Burns, A., \& Kapur, N. (2009). Suicide in dementia: a 9-year national clinical survey in England and Wales. Br J Psychiatry, 194, 175-180.

Ricciardi, A., McAllister, V., \& Dazzan, P. (2008). Is early intervention in psychosis effective? Epidemiol Psichiatr Soc, 17(3), 227-235.

Schaffer, A., Flint, AJ., Smith, E., Rothschild, AJ., Mulsant, BH., Szanto, K. et al. (2008). Correlates of suicidality among patients with psychotic depression. Suicide Life Threat Behav, 38(4), 403-414.

Schwartz, RC., \& Smith, SD. (2004). Suicidality and psychosis. The predictive potential of symptomatology and insight into illness.

J Psychiatric Res, 38(2), 185-191.

Szanto, K., Mulsant, BH., Houck, P., Dew, MA \& Reynolds, CF 3rd. (2003). Occurrence and course of suicidality during short-term treatment of late-life depression. Arch Gen Psychiatry, 60(6), 610-617. Waern, M., Runeson, BS., Allebeck, P., Beskow, J., Rubenowitz, E., Skoog, I. et al. (2002). Mental disorder in elderly suicides: a case-control study. Am J Psychiatry, 159, 450-455.

Yang, CH., Tsai, SJ., \& Hwang, JP. (2005). The efficacy and safety of quetiapine for treatment of geriatric psychosis. J Psychopharmacol, 19, 661-666. 